\author{
М.А. Егорова, А.В. Чурилов, Ю.А. Талалаенко, Е.Д. Мирович
}

ГОО ВПО «Донецкий национальный медицинский университет имени М. Горького», Донецк

\title{
ИСПОЛЬЗОВАНИЕ СИТУАЦИОННЫХ ЗАДАЧ НА КАФЕДРЕ АКУШЕРСТВА И ГИНЕКОЛОГИИ КАК СПОСОБ АКТИВИЗАЦИИ УЧЕБНО-ПОЗНАВАТЕЛЬНОЙ ДЕЯТЕЛЬНОСТИ СТУДЕНТОВ
}

В условиях современности перед высшей школой стоит важнейшая задача - повышать качество подготовки специалистов. Это связано с предъявлением новых требований к системе высшего профессионального образования условиями развития современного общества. Необходимо постоянно совершенствовать учебный процесс в связи со сменой социальных ценностей, приоритетов [1]. Радикального изменения требует тактика и стратегия обучения в вузе. Компетентностью в совокупности с умением клинически мыслить должен обладать современный выпускник медицинского вуза.

Будущий специалист должен достичь такого уровня профессиональной компетенции, который создаст условия для саморазвития личности, профессиональной и социальной реализации творческих способностей. То есть осуществляется переход к концепции личностно ориентированного образования [2, 3].

В связи с этим наиболее актуальной является разработка оптимальных методов обучения, гарантирующих формирование у студентов высшей медицинской школы более глубоких знаний, обеспечивающих им качественное выполнение профессиональной деятельности врача широкого профиля.

Специфическая составляющая клинического мышления отражает именно медицинские знания и умения. Неспецифическая, логическая составляющая включает в себя закономерности продуктивного мышления. Таким образом, логичным шагом развития педагогической практики и требованием времени является развитие клинического мышления студентов медицинского вуза. Следует отметить, что самостоятельная познавательная деятельность учащихся, их творческое мышление как ключевой элемент результата образования и являются характерными особенностями клинического мышления.

Развитие активных методов обучения, в том числе использование ситуационных задач, обусловлено именно тем, что перед обучением поставлены цели не только по усвоению студентами знаний, но и по формированию клинического мышления с развитием творческих и коммуникативных способностей, определению личностного подхода к возникшей проблеме [4] .

$\mathrm{K}$ качеству профессиональной подготовки студентов медицинских вузов относится не только количество полученных знаний, но и возможность применения этих знаний для решения многочисленных, стоящих перед врачом диагностических, лечебных и профилактических задач. Ведь умение найти выход из самой сложной клинической ситуации самостоятельно в первую очередь определяется степенью развития клинического мышления [2, 5].

На кафедре акушерства и гинекологии ГОО ВПО ДОННМУ ИМ. М. ГОРЬКОГО на практических занятиях широко используются ситуационные задачи, являющиеся активной формой современного обучения.

Ситуационная задача представляет собой конкретную клиническую ситуацию, изложенную кратко, но содержащую достаточно информации для оценки и решения. Во время решения студенты осуществляют анализ и обсуждение микроситуации. Преподавателем проводится активизация участия студентов отдельными вопросами.

Целью использования ситуационных задач является закрепление полученных знаний, используя концепции и новые знания во время рассмотрения реальных жизненных ситуаций. Кроме того, студентам предоставляется возможность продемонстрировать свои знания, в том числе требующие усовершенствования. Основным преимуществом разбора ситуационных за-

(c) М.А. Егорова, А.В. Чурилов, Ю.А. Талалаенко,

Е.Д. Мирович, 2018

(c) Университетская Клиника, 2018 
дач является концентрация внимания учащихся на реальных ситуациях. Участникам предоставляется возможность работать и индивидуально, и в малых группах.

Примеры задач, разбираемых на наших занятиях, подбирались как преподавателем, так и самими учащимися. Эти примеры брались как из собственного клинического опыта, так и из историй болезней и родов, медицинских карт, клинических журналов, опыта учащихся.

Ситуационные задачи позволяют заинтересовать аудиторию. Они заостряют внимание студентов на отдельных проблемах, готовят к творческому восприятию материала. Подбор достаточно характерной и острой ситуации, соответствующей тематике проводимого практического занятия, способствует сосредоточить внимание учащихся.

Закрепить новые знания, полученные во время занятия, усовершенствовать уже полученные профессиональные умения и активизировать обмен знаниями - такие дидактические задачи решаются при разборе ситуационных заданий, активизирующих учебно-познавательную деятельность студента, побуждающих к активной мыслительной и практической деятельности в процессе овладения материалом. При этом активность преподавателя и студентов является необходимой составной частью практического занятия. Необходимыми для профессиональной деятельности знаниями, умениями и навыками студенты овладевают благодаря их активной деятельности, которая направляется педагогом. Это способствует развитию творческих способностей, умению самостоятельно решать проблему.

Наиболее распространенными способами реализации проблемного подхода в обучении являются ситуационные задачи и задания исследовательско-поискового типа. Проблемные ситуационные клинические задачи классифицируются на следующие типы [6]:

1. Задачи, которые позволяют допускать только решение вероятностное. Это является достаточно характерным для медицины, которая не является точной наукой. При этом студенты воспроизводят рассуждения, выстраивают логические связи, ориентируя обоснования на утверждение и их взаимозависимость.

2. Задачи, которые имеют неопределенность в вопросе. Они ведут к необходимости рассуждений по установлению причинно-следственных связей, утверждений, обоснований и признаков на разных стадиях течения заболевания.
3. Задачи, имеющие избыточные исходные данные, а также содержащие информацию, не использующуюся для диагностики и лечения заболевания. Такие задания имеют «информационный шум», который студент должен последовательно исключить из своей мыслительной деятельности для нахождения верного ответа.

4. Задачи с нехваткой исходных данных. Для их решения важно получить из анамнеза заболевания, инструментальных и лабораторных исследований дополнительные сведения. После самостоятельного получения студентом этой значимой информации появляется возможность осуществления диагностики и назначения терапии.

5. Задачи с частично неправильными данными в условии, включающими: данные результатов исследований разными методами; параметры, взятые на разных этапах течения болезни; введенные данные по смежным заболеваниям и т.п. Студентам для решения таких задач необходимо исключить противоречия, уточнить адекватные состоянию пациента данные, что будет способствовать правильным выводам и ответу.

6. Задачи, для решения которых дается ограниченное время, моделирующие неотложные медицинские ситуации. Решение данного вида задач ставит своей целью отработать быстроту постановки диагноза, осуществления лечебных мероприятий.

7. Задачи, для решения которых необходимо использование предметов с необычной для них функцией, решение которых способствует формированию «врачебной смекалки» в нетипичных ситуациях.

К преимуществам рассмотрения ситуационных задач относятся возможность преподавателем оценки объема изученного студентами материала, изучение случаев из практики делает обучение более осмысленным и приближенным к реальной жизни, прекрасная методика для обучения решения проблемных ситуаций, высока вовлеченность студентов в активную работу, способствуя их взаимодействию между собой.

К недостаткам могут быть отнесены возможность вызывать чувство «неловкости" у студентов при рассмотрении слишком реалистичных примеров, особенно если последние встречались в практике студентов, а также большой временной интервал, необходимый для изучения случаев из практики. Ярко выраженный практический характер ситуационной задачи является ее специфическим маркером, при этом для ее ре- 
шения необходимо конкретное знание предмета, а зачастую и несколько смежных дисциплин. Например, для решения задачи по гинекологии необходимы знания нормальной анатомии человека, патологической анатомии человека, нормальной физиологии человека и т.д. Обязательным является проблемный вопрос, сформулированный так, чтобы студент был заинтересован найти на него ответ.

Мы проводили разбор задач следующими способами:

- анализ проблемы, позволяющий проанализировать ситуацию или определить источник проблемы;

- ответ на сфокусированные вопросы;

- ответ на вопросы с широким спектром ответов, когда студенты могут высказать свою личную мысль, отвечая на вопрос;

- решение проблемы: студенты предлагают варианты решения ситуации.

При разборе в малых группах желательным было создание короткой презентации своего случая для демонстрации для другой группы. Обязательным являлось подведение итогов преподавателем после разбора задач.

Опыт разбора ситуационных задач демонстрирует способствование последних развивать навыки самостоятельной деятельности, разви- вать способность ориентироваться в изучаемом материале, повышать уровень функциональной грамотности, формировать ключевые компетентности, готовить к профессиональному выбору.

Проведенный анализ успеваемости студентов Донецкого национального медицинского университета за 2014-2017 годы показал, что в результате решения проблемных ситуационных задач на практических занятиях по акушерству и гинекологии имеет место позитивная тенденция показателей мыслительной деятельности студентов: возросла самостоятельная познавательная деятельность учащихся и творческое мышление как ключевой элемент результата образования.

Таким образом, сложным и многофакторным процессом является формирование клинического мышления у студентов медицинского вуза при решении ситуационных задач. Приобретение знаний, развитие логического компонента в клиническом мышлении врача должно быть осознанно управляемым при обучении студентов. Применение ситуационных задач по акушерству и гинекологии расширяет возможности обучающихся и способствует развитию клинического мышления при освоении медицинской специальности.

\section{М.А. Егорова, А.В. Чурилов, Ю.А. Талалаенко, Е.Д. Мирович}

ГОО ВПО «Донецкий национальный медицинский университет имени М. Горького», Донецк

\section{ИСПОЛЬЗОВАНИЕ СИТУАЦИОННЫХ ЗАДАЧ НА КАФЕДРЕ АКУШЕРСТВА И ГИНЕКОЛОГИИ КАК СПОСОБ АКТИВИЗАЦИИ УЧЕБНО-ПОЗНАВАТЕЛЬНОЙ ДЕЯТЕЛЬНОСТИ СТУДЕНТОВ}

На кафедре акушерства и гинекологии ГОО ВПО «Донецкий национальный медицинский университет имени М. Горького» на практических занятиях широко используются ситуационные задачи, являющиеся активной формой современного обучения.

Целью использования ситуационных задач является закрепление полученных знаний, используя концепции и новые знания во время рассмотрения реальных жизненных ситуаций. Кроме того, студентам предоставляется возможность продемонстрировать свои знания, в том числе требующие усовершенствования. Основным преимуществом разбора ситуационных задач является концентрация внимания учащихся на реальных ситуациях.

Опыт разбора ситуационных задач демонстрирует способствование последних развивать навыки самостоятельной деятельности, развивать способность ориентироваться в изучаемом материале, повышать уровень функциональной грамотности, формировать ключевые компетентности, готовить к профессиональному выбору. Проведенный анализ успеваемости студентов ГОО ВПО «Донецкий национальный медицинский университет имени М. Горького» за 2014-2017 годы показал, что в результате решения проблемных ситуационных задач на практических занятиях по акушерству и гинекологии имеет место позитивная тенденция показателей мыслительной деятельности студентов: возросла самостоятельная познавательная деятельность учащихся и творческое мышление как ключевой элемент результата образования.

Ключевые слова: ситуационные задачи, творческое мышление, познавательная деятельность. 


\section{M.A. Egorova, A.V. Churilov, Y.A. Talalayenko, E.D. Mirovich}

SEI HPE «M. Gorky Donetsk National Medical University», Donetsk

\section{USE OF SITUATIONAL TASKS AT THE DEPARTMENT OF OBSTETRICS AND GYNECOLOGY AS A METHOD OF ACTIVATION THE STUDENTS' LEARNING AND COGNITIVE ACTIVITY}

At the Department of Obstetrics and Gynecology at SEI HPE «M. Gorky Donetsk National Medical University» situational tasks, which are an active form of modern teaching, are widely used in practical classes.

The purpose of using situational tasks is to consolidate the lessons learned, using concepts and new knowledge during the examination of real life situations. In addition, students are given the opportunity to demonstrate their knowledge, including those, which require improvement. The main advantage of the analysis of situational tasks is to focus students' attention on real life situations.

The experience of the analysis of situational tasks demonstrates the contribution of the latter into the de- velopment of independent activity skills, development of the ability to orientate in the studied material, improvement of functional literacy level, formation of key competencies and preparation for professional choice. The analysis of the students' progress at SEI HPE «M. Gorky Donetsk National Medical University» for 2014-2017 years showed, that as a result of solving situational problems in practical classes in obstetrics and gynecology, there is a positive tendency in indicators of students' mental activity: both students' independent cognitive activity and creative thinking have increased as a key element of the result of education.

Key words: situational tasks, creative thinking, cognitive activity.

\section{ЛИТЕРАТУРА}

1. Казакова А.Г. Основы педагогики высшей школы. М.: ИПО ПРОФИЗДАТ; 2000. 124.

2. Парахонский А.П. Развитие продуктивного мышления студентов посредством стимулирования самостоятельной работы. Современные наукоемкие технологии. 2009; 9: 129-130.

3. Горшунова Н.К. Инновационные технологии в подготовке врача в систе-ме непрерывного профессионального образования. Фундаментальные исследования. 2009; 2: 86-88.

4. Ступина С.Б. Технологии интерактивного обучения в высшей школе: Учебно-методическое пособие. Саратов: Издательский центр «Наука»; 2009. 52.

5. Гатауова М.Р. Применение инновационных методов обучения педиатрии для студентов факультета общей медицины. Инновации в науке. 2013; 23: 137-140.

6. Артюхина А.И., Чумаков В.И. Интерактивные методы обучения в медицин-ском вузе: Учебное пособие. Волгоград: ВолГМУ; 2011. 32.

\section{REFERENCES}

1. Kazakova A.G. Osnovyi pedagogiki vyisshey shkolyi [Fundamentals of education of higher school]. M.: IPO PROFIZDAT; 2000. 124 (in Russian).

2. Parahonskiy A.P. Razvitie produktivnogo myishleniya studentov posredstvom stim-ulirovaniya samostoyatelnoy rabotyi [Development of productive thinking of students by means of independent work stimulation]. Sovremennyie naukoemkie tehnologii. 2009; 9: 129-130 (in Rus-sian).

3. Gorshunova N.K. Innovatsionnyie tehnologii v podgotovke vracha $\mathrm{v}$ sisteme neprery-ivnogo professionalnogo obrazovaniya [Innovative technologies in training of doctors in the system of continuous professional education]. Fundamentalnyie issledovaniya. 2009; 2: 86-88 (in Russian).

4. Stupina S.B. Tehnologii interaktivnogo obucheniya v vyisshey shkole: Uchebno-metodicheskoe posobie [Technologies of interactive training at higher school: Educational and me-thodical manual]. Saratov: Izdatelskiy tsentr «Nauka»; 2009. 52 (in Russian).

5. Gatauova M.R. Primenenie innovatsionnyih metodov obucheniya pediatrii dlya stu-dentov fakulteta obschey meditsinyi [Application of methods in teaching pediatrics to the students of the general medicine faculty]. Innovatsii v nauke; 23:137-140 (in Russian).

6. Artyuhina A.I., Chumakov V.I. Interaktivnyie metodyi obucheniya $\mathrm{v}$ meditsinskom vuze: Uchebnoe posobie [Interactive methods of teaching at medical university: Education guid-ance]. Volgograd: VolGMU; 2011. 32 (in Russian). 